Study of carbon dust for mat i on and thei $r$ structure usi ng i nduct i vel y coupl ed pl asmas under hi gh at om c hydrogen i rradi at i on

\begin{tabular}{|c|c|}
\hline 著者 & $\begin{array}{l}\text { Takeguchi Yuj i, Kyo M, Uesugi Yoshi hi ko, } \\
\text { Tanaka Y., Masuzaki Sugur u }\end{array}$ \\
\hline $\begin{array}{l}\text { jour nal or } \\
\text { publ i cat } i \text { on title }\end{array}$ & Jour nal of Nucl ear Nat eri al s \\
\hline nunber & $390-391$ \\
\hline page $r$ ange & 188 191 \\
\hline year & 2009-06-15 \\
\hline URL & ht t p: //hdl . handl e. net /2297/17434 \\
\hline
\end{tabular}




\title{
Study of Carbon Dust Formation and their Structure using Inductively Coupled Plasmas under High Atomic Hydrogen Irradiation
}

\author{
Y. Takeguchi ${ }^{\mathrm{a}}$, M. Kyo ${ }^{\mathrm{a}}$, Y. Uesugi ${ }^{\mathrm{a}}$, Y. Tanaka ${ }^{\mathrm{a}}, \mathrm{S}$. Masuzaki $^{\mathrm{b}}$ \\ ${ }^{a}$ Division of Electrical and Computer Science Kanazawa University, Kakuma,920-1192, Japan \\ ${ }^{\mathrm{b}}$ National Institute for Fusion Science, Toki, Japan
}

\begin{abstract}
Experiments on erosion and dust formation on graphite materials have been performed using high power induction plasmas containing high atomic hydrogen flux $\left(\sim 10^{24} \mathrm{~m}^{-2} \mathrm{~s}^{-1}\right)$. Chemical sputtering by atomic hydrogen irradiation with incident energy below $1 \mathrm{eV}$ eroded the graphite targets significantly, and the sputtering yield was roughly estimated to be $0.002-0.005$, which is as high as that obtained by ion beam and fusion plasma experiments. The transport of the released hydrocarbon along the gas flow, interacting with low temperature plasmas, results in carbon dust formation on the eroded graphite target and also on the silicon and graphite samples located at the remote position. The dust size and density observed on the samples decreases with distance from the graphite target. The dust shape strongly depends on the target surface temperature, and the graphite dust turns into polyhedral particle like diamond when the surface temperature rises to 1100 K.
\end{abstract}

PACS: 52.40.Hf, 81.05.Uw, 81.15.Cd, 79.20.Rf

JNM keywords: Carbon, Erosion, Irradiation, Plasma-Material Interaction, Sputtering

PSI-18 keywords: Graphite, Dust, Chemical Sputtering, Detached plasma, Hydrogen atoms

*Corresponding author address: Kakuma, Kanazawa, 920-1192, Japan

*Corresponding author E-mail: 1027take@ee.t.kanazawa-u.ac.jp

Presenting author: Yuji Takeguchi

Presenting author e-mail: 1027take@ee.t.kanazawa-u.ac.jp 


\section{Introduction}

Carbon materials, such as isotropic graphite, and carbon fiber reinforced composites (CFC) are superior plasma facing components, which are used in a fusion reactor because of their high thermal conductivity and tensile strength. Divertor graphite tiles, however, are eroded significantly by irradiation with high particle and heat flux divertor plasmas. Sputtering erosion and dust formation of carbon materials have significant effects on reactor performance, such as tritium retention, impurity release, degradation of vacuum sealing, and electrical isolation, etc. So far several methods to reduce the divertor plasma heat load have been tested and it is recognized that the detached divertor plasma operation [1] is the most viable for a fusion reactor. Although the detached divertor works well for heat load reduction, the graphite erosion by irradiation of low energy hydrogen ions and atoms in the detached divertor plasma is not yet understood. It is very important to examine plasma surface interactions and dust formation mechanisms in detached divertor plasmas for future reactor designs. Graphite erosion and dust formation mechanism has been studied using high pressure Inductively Coupled Plasmas (ICPs) [2].

\section{Experimental setup}

Figure 1 shows a schematic diagram of a plasma irradiation system. In this paper, experiments were performed by irradiating argon-hydrogen mixture (gas flow rate, Ar: 60 slpm H2: 0, 2, 8 slpm) plasma to six targets. The MOSFET inverter power supply with maximum rf power of $50 \mathrm{~kW}$ and at a frequency of $\sim 450 \mathrm{kHz}$ was used for the power supply of ICPs. The authors set input power level of $15 \mathrm{~kW}$ in this experiment. One graphite target (IG-430U fabricated by TOYO Tanso Co.) is located under the plasma torch and five other graphite or silicon crystal targets, with diameters of $15 \mathrm{~mm}$, are placed at different positions to determine how the irradiation condition affects graphite target erosion and dust formation. The target surface temperature is not actively controlled in this experiment. The surface temperature is indirectly controlled by changing the experimental conditions, such as the input power, position of the induction coil and so on.

\section{Results and discussion}

\subsection{Plasma parameter of ICP}

In this paper, we describe the results of experiments where plasma parameters (atomic hydrogen flux, hydrogen ion flux and electron temperature) have been varied in high power ICPs . Electron temperature, electron density and ion flux were measured by Langmuir probes. Probe measurements of $\mathrm{Ar} / \mathrm{H}_{2}$ mixture plasmas in these experiments show that the electron temperature and electron densities near the target position 1 , and ion fluxes onto the target 1 are in the range $0.5-1.5 \mathrm{eV}$, $10^{16}-10^{17} \mathrm{~m}^{-3}$ and $10^{19}-10^{20} \mathrm{~m}^{-2} \mathrm{~s}^{-1}$ respectively. On other hand, atomic hydrogen density and hydrogen ion density have been estimated using electromagnetic fluid simulation under local thermodynamic equilibrium [3]. Figure 2 shows the estimated atomic hydrogen and hydrogen ion densities as a function of the $\mathrm{H}_{2}$ gas flow rate. These results from ICP simulations indicate that the degree of ionization is below $0.1 \%$, and that the dominant particles bombarding the graphite target in the experimental conditions investigated are atomic hydrogen, not ions. In addition, it is estimated that atomic hydrogen flux is as high as $10^{23}-10^{24} \mathrm{~m}^{-2} \mathrm{~s}^{-1}$.

From these results, we conclude that high power ICPs have characteristic features, such as a high particle flux (ion flux: $10^{19}-10^{20} \mathrm{~m}^{-2} \mathrm{~s}^{-1}$, atomic hydrogen flux: $\left.10^{23}-10^{24} \mathrm{~m}^{-2} \mathrm{~s}^{-1}\right)$, high heat flux $(\sim 1$ $\left.\mathrm{MW} / \mathrm{m}^{2}\right)$, and low temperature $(\sim 1 \mathrm{eV})$. Although the working gas pressure is high $(\mathrm{P} \sim 5 \mathrm{kPa})$, these features are very important for studying the fundamental mechanism of carbon erosion and dust formation in detached plasmas, where atomic and molecular hydrogen particles play a import role in plasma-material interactions.

\subsection{Graphite target erosion by atomic hydrogen irradiation}

After 180 minutes plasma irradiation in our experiments, graphite and/or silicon targets were collected and their weights were measured to have the mass change of the graphite target before and after $\mathrm{Ar} / \mathrm{H}_{2}$ plasma irradiation. Table 1 shows weight loss of graphite target by $\mathrm{Ar} / \mathrm{H}_{2}$ plasma 
irradiation. This table indicates that significant erosion has taken place on the graphite targets facing the plasma (No. 1-3). On the contrary, targets placed in the shadow region (No. 4-6) were not eroded. The maximum erosion rate was observed in graphite target 1, which was irradiated directly by both hydrogen ions and atoms. The erosion rate decreases rapidly with distance from the target to the plasma. With addition of hydrogen into Ar plasmas, graphite target erosion is strongly enhanced. Graphite target erosion depends on the combination of the hydrogen flow and of the substrate temperature. We attribute the measured graphite erosion by pure argon plasma irradiation to Radiation Enhanced Sublimation (RES) in our experiments. Figure 3 shows the radiation spectra from the plasma at $5 \mathrm{~mm}$ above the graphite target 1 during $\mathrm{Ar}$ and $\mathrm{Ar} / \mathrm{H}_{2}$ plasma irradiation. With addition of hydrogen, the band spectra of $\mathrm{CH}$ and $\mathrm{C}_{2}$ are observed clearly, which is a good indication of chemical sputtering by atomic hydrogen. A rough estimation of the chemical sputtering yield by low energy atomic hydrogen irradiation is $0.002-0.005$ as shown in Figure 4, which is close to the values obtained in energetic beam irradiation experiments [4] and fusion plasma experiments [5]. In our experiments, the chemical sputtering yield is estimated by measuring the weight loss of the graphite target and the hydrogen gas feed rate. Since the electromagnetic fluid simulation of the induction plasmas shows that most of the hydrogen molecules introduced into the induction plasmas are dissociated into atomic hydrogen in the core region, the influx of atomic hydrogen is estimated on the basis that the introduced hydrogen particles are fully dissociated in the core plasma and that the generated atomic hydrogen particles are carried equally downward along the cross sectional area of the plasma column.

\subsection{Dust formation on the targets}

Figures 5(a)-(f) show SEM pictures of carbon dust particles observed on the graphite and silicon targets at different locations. These targets were exposed to argon-hydrogen mixture plasmas for 180 minutes. Dust particles with characteristic shapes have been found on graphite and silicon targets placed at both open and shadow areas, as shown in this figure. Figure 6 (a)-(c) shows particle size distribution of carbon dust particles observed on the target 1-3. The observed particle size ranges from a submicron to about $10 \mu \mathrm{m}$. The average size of the dust particles becomes small and their density decreases with distance from the main irradiation region. The shape of the dust strongly depends on the target surface temperature $T_{s}$. When $T_{s}$ is higher than $1100 \mathrm{~K}$, the carbon dust exhibits a polyhedral shape like diamond, as shown in Fig. 5(a), and it shows ball, agglomeration, granular or fiber shapes when $T_{s}<1100 \mathrm{~K}$. The flake shape, as shown in Fig. 5(f), is formed by graphite coming off the target. From these observations, we can conclude that growth and structural formation of dust particles proceeds faster and is advanced in the target 1 , where the dominant plasma-material interactions occur, than in the remote target. Preliminary experiments of $\mathrm{CH}_{4}$ gas injection into Ar plasmas show that ball type graphite particles covered the whole surface of the graphite target and no other type of carbon dust particles were not found. This indicates that simultaneous irradiation of hydrocarbon and hydrogen particles on to the material surface with plasma must play an important role in carbon dust formation.

\section{Conclusions}

From these experimental observations, a rough description of the process of graphite target erosion to dust formation is summarized in Figure 7. Graphite targets are significantly eroded by irradiation of $\mathrm{Ar} / \mathrm{H}_{2}$ plasmas with high atomic hydrogen flux to generate hydrocarbon particles $\mathrm{C}_{\mathrm{x}} \mathrm{H}_{\mathrm{y}}$ by the chemical sputtering. The released hydrocarbon particles are dissociated by the surrounding low temperature plasmas and carried along the gas flow to reach the sample surfaces located in remote and shadow regions. In this experiment, high flux and low energy atomic hydrogen particles bring significant graphite erosion by chemical sputtering. Carbon dusts, which have various shapes depending on the irradiation condition, are formed and scattered on the graphite target even in the erosion dominant condition. SEM picture of many different dust shape suggest that the dust particle growth occurs on the target surface. The experimental results indicate that the particle of polyhedral shape or other shapes depends strongly on the target surface temperature. Increasing the surface temperature of the graphite and silicon targets up to $1100 \mathrm{~K}$ turns the graphite 
granular particles into polyhedral shape like diamond. In addition to the present experiments the knowledge of surface coating and film formation in industrial plasma applications will help us to understand the dust formation process in fusion device.

\section{Acknowledgements}

This work was supported by the NIFS budged NIFS05KOAP013.

\section{References}

[1] D. Lumma, J. L. Terry, and B. Lipshultz, Phys. Plasmas 4, 2555 (1997).

[2] Y. Tanaka et al., Appl. Phys. Lett., vol.89, No.3, 031501, (2006)

[3] S. A. Al-Mamun et al.: $\mathrm{CO}_{2}$ and $\mathrm{H}_{2}$ gas mixture inclusion effect on shrinkage of Ar induction thermal plasmas, IEEJ Trans. PE, vol.128, No.2, (2008)

[4] E. Vietzke and A. A. Haasz, Chemical Erosion, in physical processes of the interaction of fusion plasmas with solids (Academic Press. Inc., San Diego 1996) p.135

[5] J. Roth, J. Nucl. Mater. 266-269 (1999) 55

\section{Table captions}

Tab. 1 weight loss of graphite target by $\mathrm{Ar} / \mathrm{H}_{2}$ plasma irradiation.

\section{Figure captions}

Fig. 1 Schematic diagram of atomic hydrogen irradiation system using high power ICP.

Fig. 2 Atomic hydrogen and hydrogen ion density as a function of the $\mathrm{H}_{2}$ gas flow rate obtained by fluid simulation.

Fig. 3 Radiation spectra from the plasma at $5 \mathrm{~mm}$ above graphite target 1 during $\mathrm{Ar}$ (dotted line) and $\mathrm{Ar} / \mathrm{H}_{2}$ (solid line) plasma irradiation.

Fig. 4 Temperature dependence of chemical sputtering yield estimated by the weight loss of graphite targets.

Fig. 5 SEM pictures of carbon dust on the graphite targets and silicon crystal targets. Surface temperature during plasma irradiation is shown in the figure.

Fig. 6 Size distribution of dust particle on the target 1-3

Fig. 7 Schematic illustration of erosion and dust formation in the present experiments 


\section{Tables}

Tab. 1 weight loss of graphite target by $\mathrm{Ar} / \mathrm{H}_{2}$ plasma irradiation.

Scale Table size : double $(150 \mathrm{~mm})$ journal column width

\begin{tabular}{|l||c|c|c||c|c|c|}
\hline & Pos.1 & Pos.2 & Pos. 3 & Pos.4 & Pos.5 & Pos.6 \\
\hline \hline Ar:60 slpm, $\mathrm{H}_{2}: 0 \mathrm{slpm}$ & $4.4 \mathrm{mg}$ & $2.7 \mathrm{mg}$ & $2 \mathrm{mg}$ & $0.2 \mathrm{mg}$ & $0.1 \mathrm{mg}$ & $-0.5 \mathrm{mg}$ \\
\hline Ar:60 slpm, $\mathrm{H}_{2}: 2 \mathrm{slpm}$ & $35.4 \mathrm{mg}$ & $36.6 \mathrm{mg}$ & $5.3 \mathrm{mg}$ & $-0.2 \mathrm{mg}$ & $0.2 \mathrm{mg}$ & $0.4 \mathrm{mg}$ \\
\hline Ar:60 slpm, $\mathrm{H}_{2}: 8 \mathrm{slpm}$ & $88.2 \mathrm{mg}$ & $95.6 \mathrm{mg}$ & $19.4 \mathrm{mg}$ & $-0.2 \mathrm{mg}$ & $0.4 \mathrm{mg}$ & $0.3 \mathrm{mg}$ \\
\hline
\end{tabular}




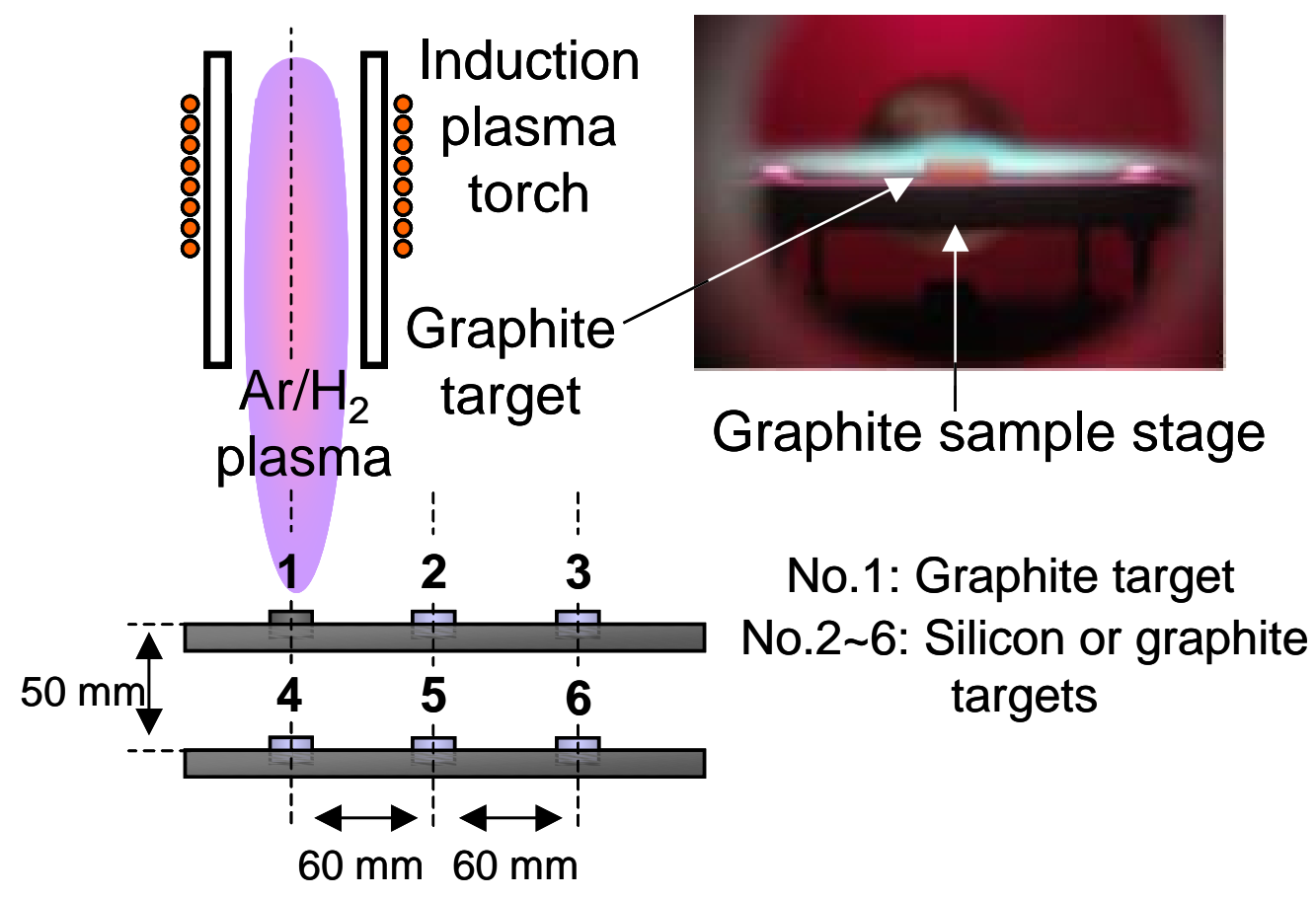

Fig. 1 Schematic diagram of atomic hydrogen irradiation system using high power ICP.

Scale figure size : single $(75 \mathrm{~mm})$ journal column width. 


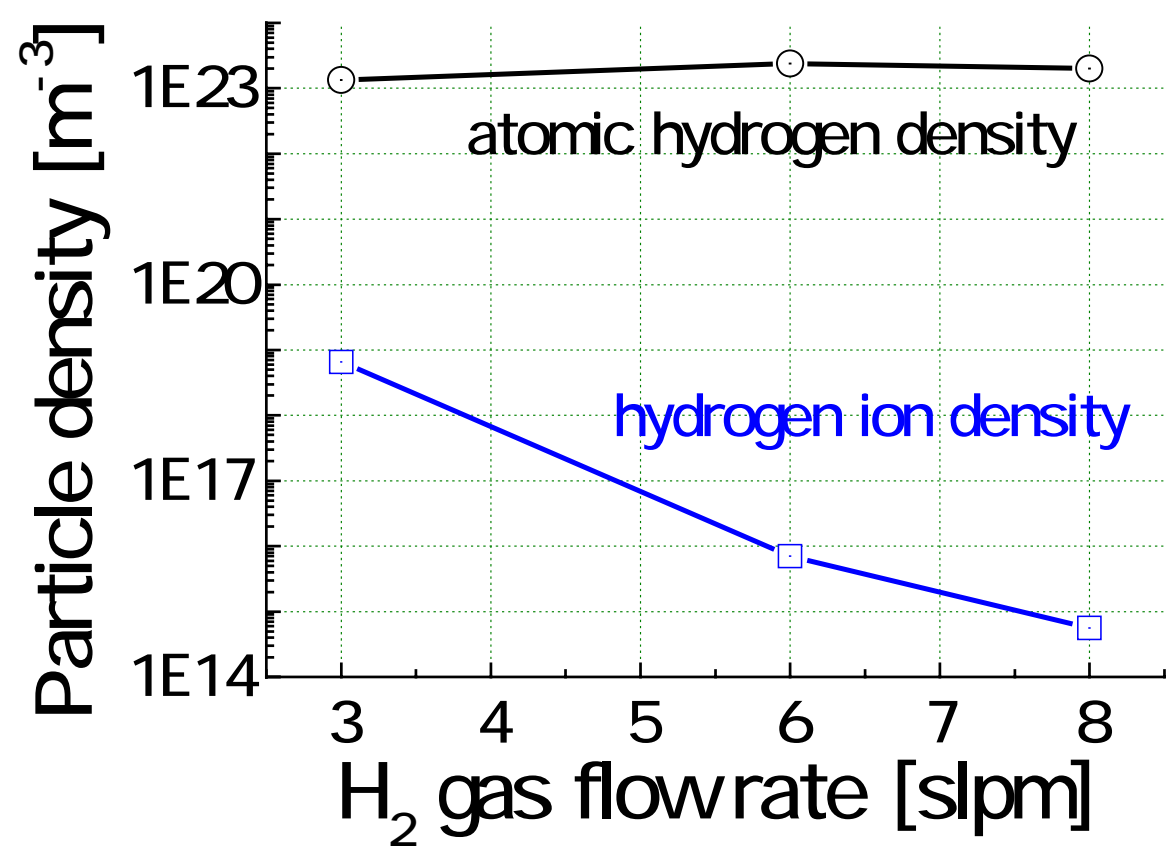

Fig. 2 Atomic hydrogen and hydrogen ion density as a function of the $\mathrm{H}_{2}$ gas flow rate obtained by fluid simulation.

Scale figure size : Single $(75 \mathrm{~mm})$ journal column width. 


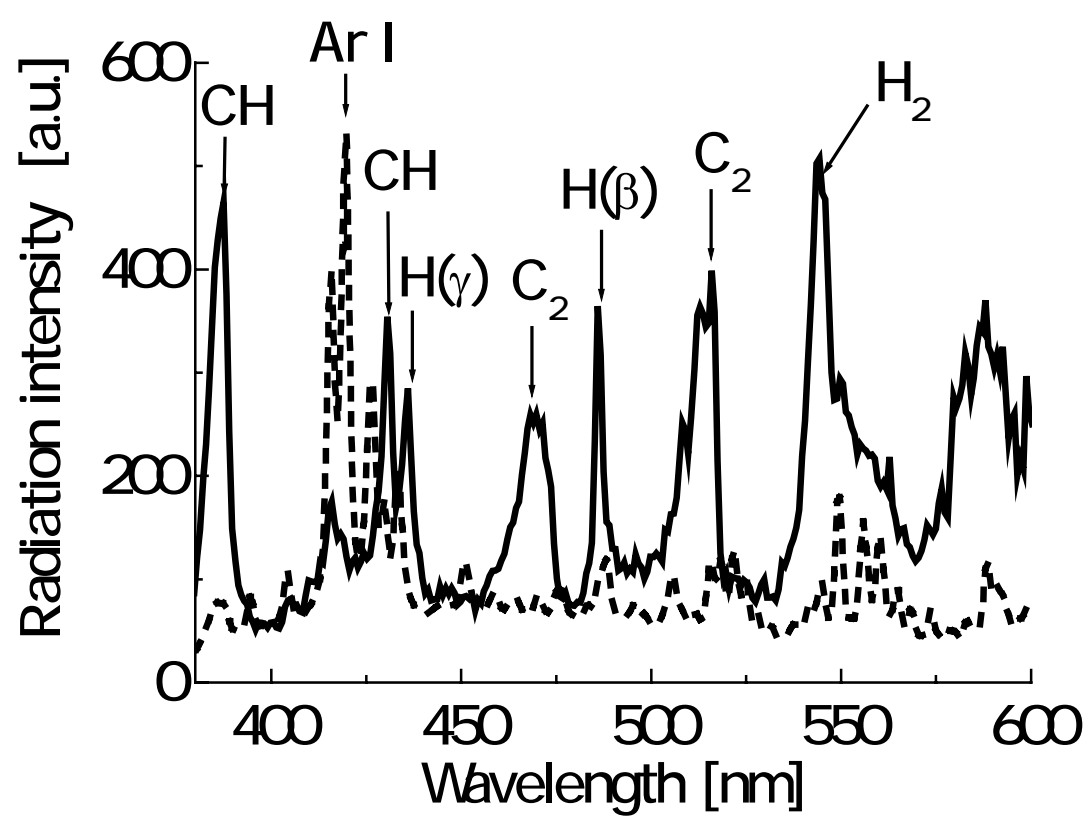

Fig. 3 Radiation spectra from the plasma at $5 \mathrm{~mm}$ above graphite target 1 during $\mathrm{Ar}$ (dotted line) and $\mathrm{Ar} / \mathrm{H}_{2}$ (solid line) plasma irradiation.

Scale figure size : Single $(75 \mathrm{~mm})$ journal column width. 


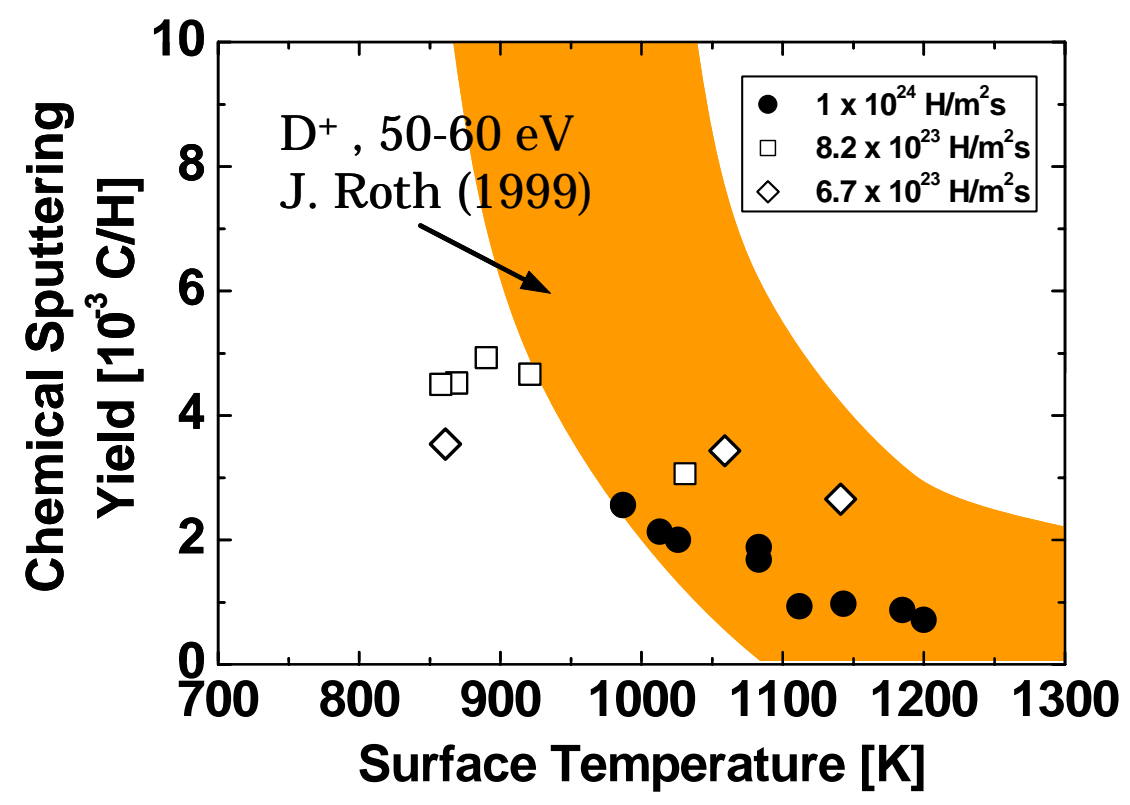

Fig. 4 Temperature dependence of chemical sputtering yield estimated by the weight loss of graphite targets. Scale figure size : Single $(75 \mathrm{~mm})$ journal column width. 


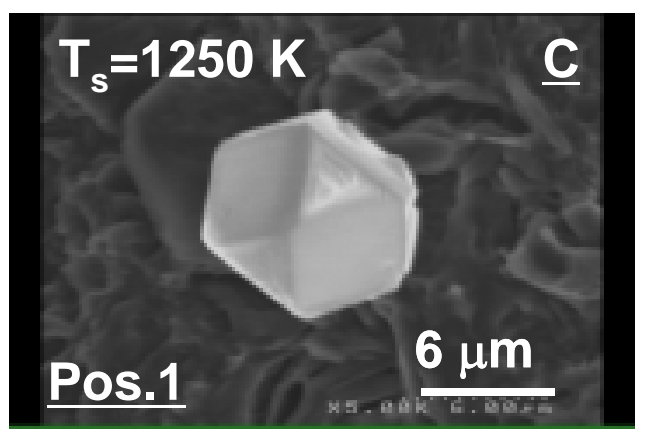

(a) diamond-type $\mathrm{T}_{\mathrm{s}}=900 \mathrm{~K}$ $\underline{\text { si }}$

Pos.2

(c) ball-type

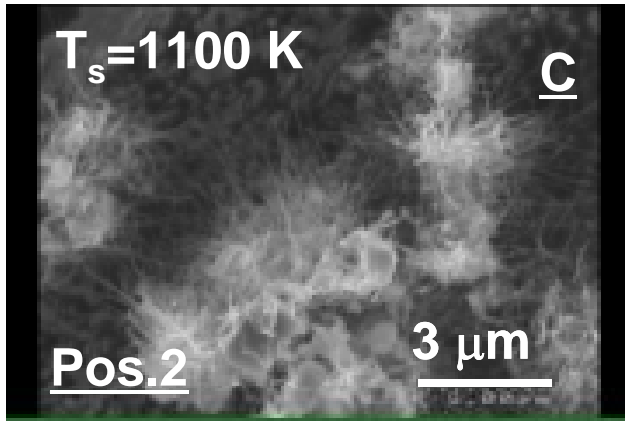

(e) fiber-type

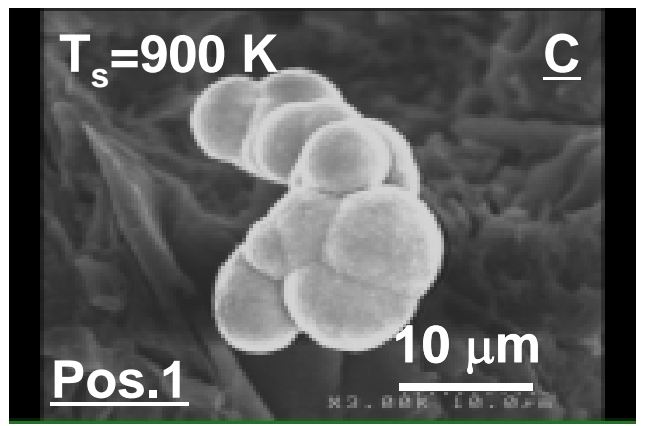

(b) granular-type

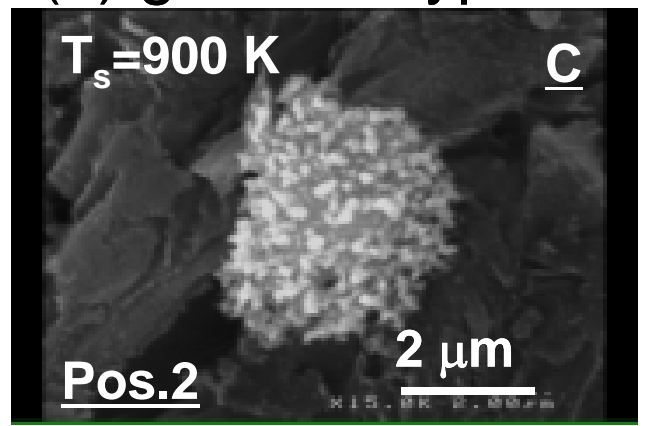

(d) agglomeration-type

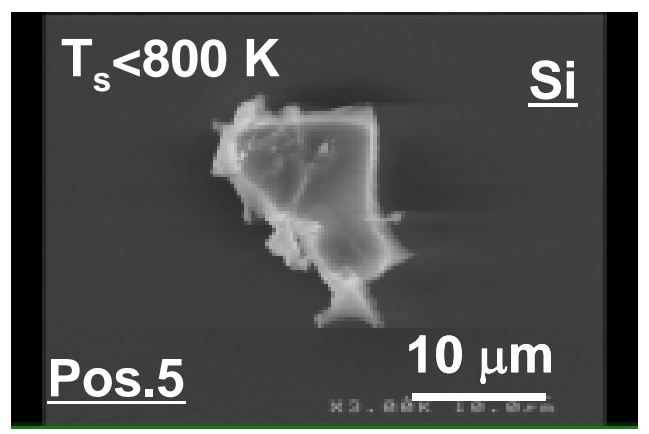

(f) flake-type

Fig. 5 SEM pictures of carbon dust on the graphite targets and silicon crystal targets. Surface temperature during plasma irradiation is shown in the figure.

Scale figure size : Single $(75 \mathrm{~mm})$ journal column width 

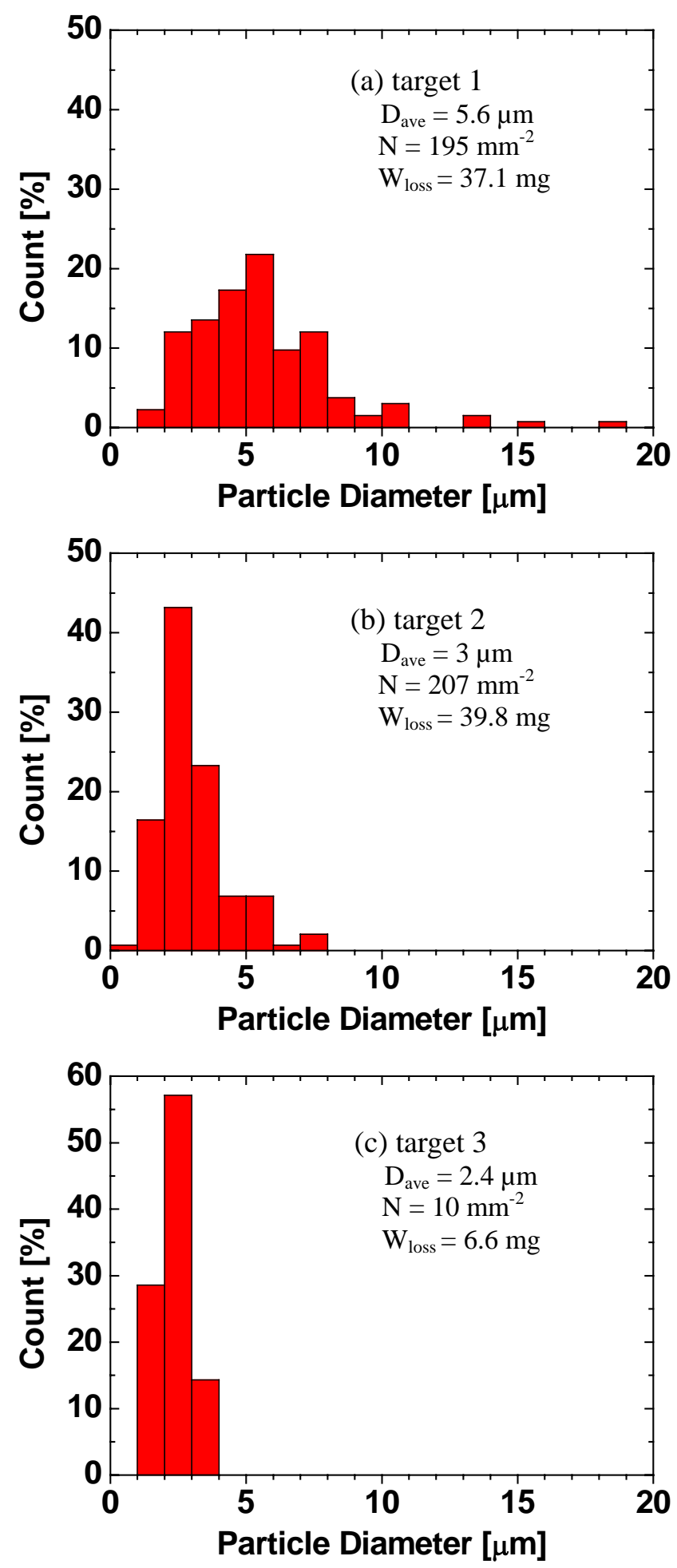

Fig. 6 Size distribution of dust particle on the target 1-3

Scale figure size : Single $(75 \mathrm{~mm})$ journal column width 


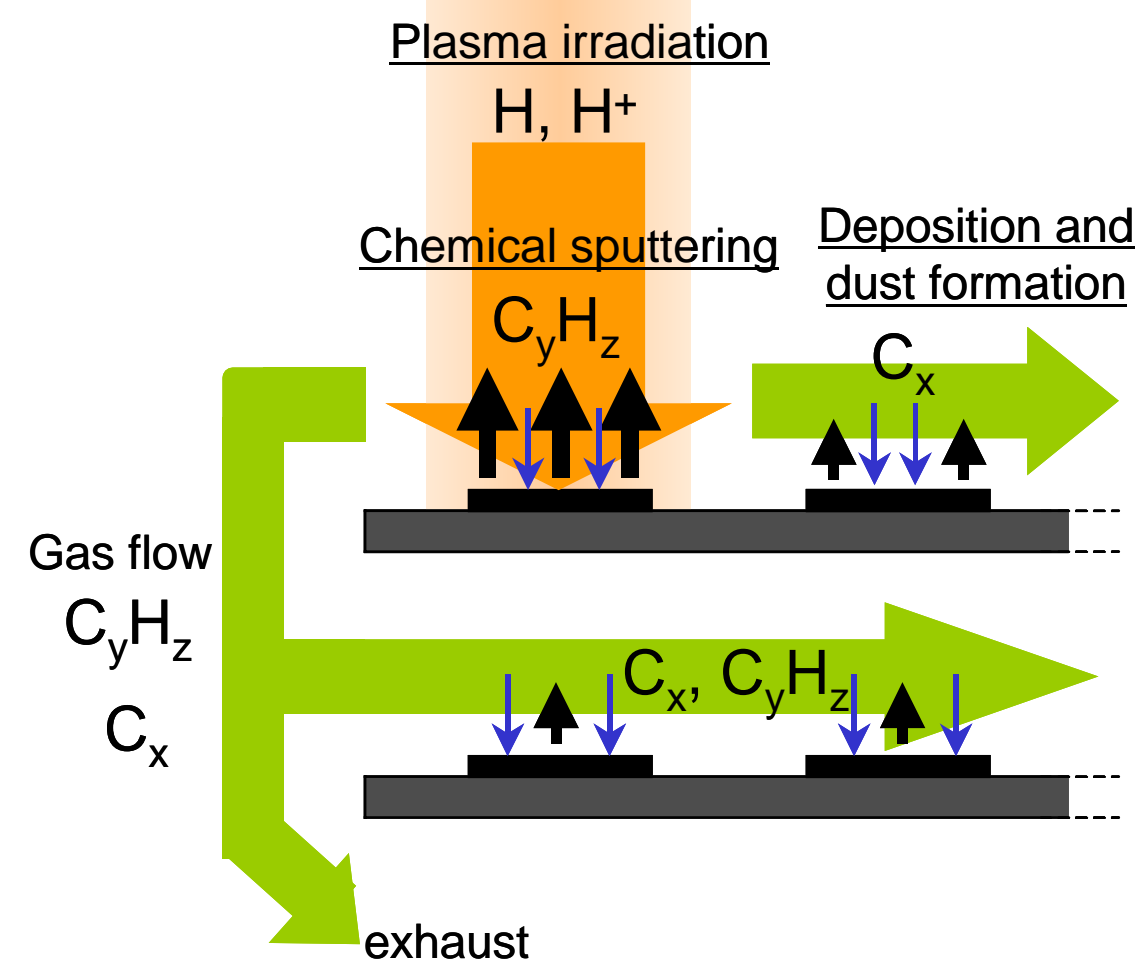

Fig. 7 Schematic illustration of erosion and dust formation in the present experiments

Scale figure size: Single $(75 \mathrm{~mm})$ journal column width 